\title{
„Es knackt so beim Atmen“
}

\section{Ein 73-jähriger, adipöser Patient stellt sich mit Knacken an der linken Schulter beim Atmen vor.}

Er berichtet in unserer hausärztlichen Praxis, dass es am Tag zuvor bei einer starken Hustenattacke im Rahmen seiner langjährig bekannten COPD plötzlich „links oben“ kurz stark geschmerzt hätte und jetzt bei tiefer Atemexkursion an diese Stelle „knacken“ würde. Auskultatorisch zeigt sich die Lunge in allen Abschnitten seitengleich belüftet, links parasternal kann bei tiefer In- und Exspiration ein Knackgeräusch/Reiben getastet werden. Die bekannte Dyspnoe ist anamnestisch nicht verschlechtert: $\mathrm{pO}_{2} 92 \%$. RR 130/80 mmHg, 80 bpm rhythmisch. Keine gestauten Halsvenen. EKG und Röntgenthorax zeigten keinen wegweisenden Befund. Eine Pleuritis (Pleurareiben) und eine geplatzte Emphysemblase konnten ausgeschlossen werden. Bei bekannter alter Rippenserienfraktur wurde daraufhin eine Rippengitteraufnahme durchgeführt. Hier zeigten sich links lateral alte Frakturen der 2.-7. Rippe mit Pseudarthrosenbildung. So hatte sich wohl beim starken Husten die Pseudarthrose einer Rippe teilweise gesprengt, was die Schmerzen und das Knackgeräusch erklärte. Der Patient wurde über die Harmlosigkeit des Befundes aufgeklärt. Eine analgetische Therapie wurde eingeleitet.

Dr. med. Alexandra Müller, Dr. med. Daniel Möbius, Dr. med. RudolfK. Merkl, Praxis "meinedoktoren.com", Marienstraße 6, 92224 Amberg

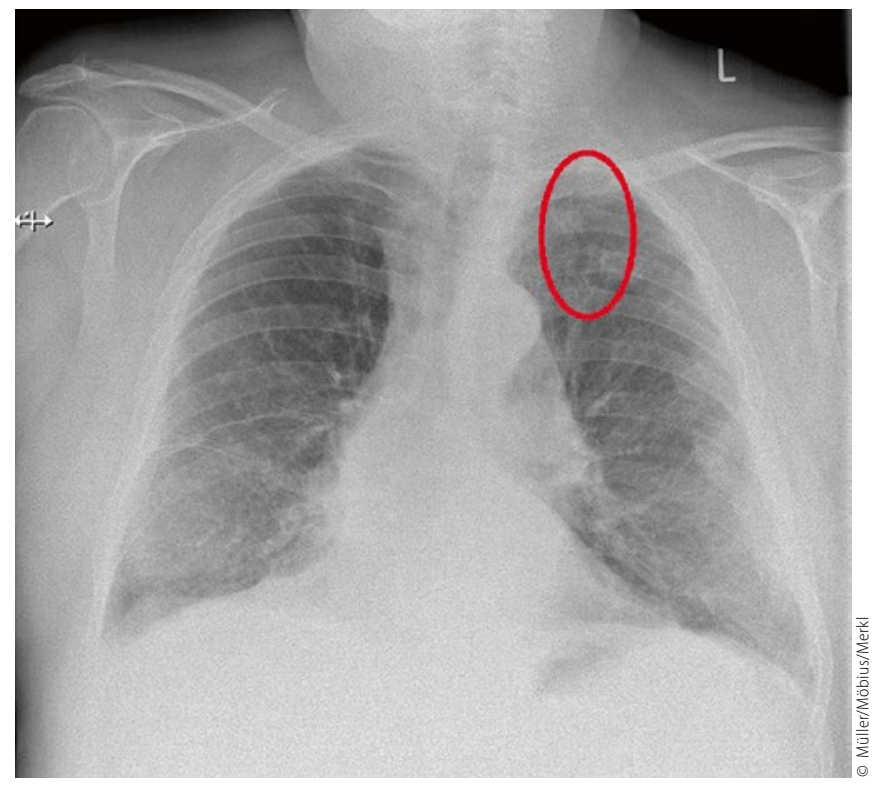

Alte Frakturen der 2.-7. Rippe mit Pseudarthrosenbildung.

\section{Verdacht auf Bronchopneumonie}

\section{Fehldiagnose durch unvollständigen Check}

\begin{abstract}
Wie wichtig eine sorgfältige Untersuchung aller Körperregionen ist, zeigt folgender Fall. Als eine ältere, demente Patientin mit unklarem Fieber zur stationären Aufnahme kam, wurde zunächst der Verdacht auf eine Bronchopneumonie geäußert. Erst am Folgetag fiel eine Gesäßschwellung auf ...
\end{abstract}

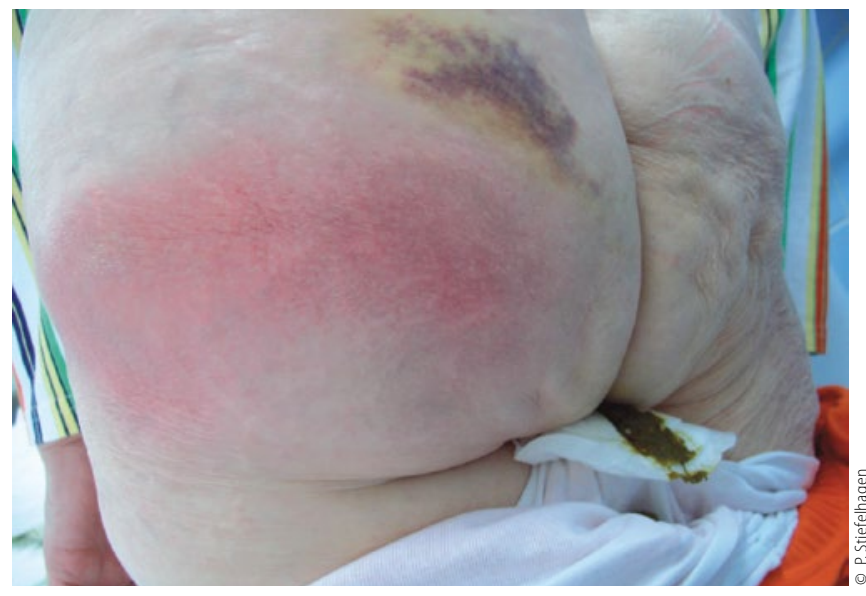

Rötlich-bläuliche Gesäßschwellung mit Überwärmung.
Eine 72-Jährige mit seniler Demenz wurde wegen unklaren Fiebers mit leichter Dyspnoe/Tachypnoe stationär eingewiesen. Eine eigene Anamnese konnte nicht erhoben werden. Vom diensthabenden Arzt wurden feinblasige klingende Rasselgeräusche über dem rechten Lungenunterfeld auskultiert und im Röntgen dort fragliche beginnende Infiltrationen beschrieben. Die Entzündungswerte waren erhöht: BSG 54/86 mm n.W., 15.800 Leukos/ nl, CRP 16 mg/dl. Diagnose: Bronchopneumonie. Es wurde eine Antibiose mit Cephalosporin eingeleitet. Am nächsten Tag wurde vom Pflegepersonal eine rot-blaue, überwärmte Schwellung am linken Gesäß entdeckt, die schmerzte. Bei der Sonografie fand sich ein großes Flüssigkeitsdepot: ein intraglutealer Abszess. Die genauere Befragung der Angehörigen ergab, dass die Frau ca. 1 Woche zuvor gestürzt war. Anzunehmen ist, dass sie sich ein Hämatom zugezogen hatte, das sich infizierte. Der Abszess wurde drainiert und heilte komplikationslos ab. Dr. med. Peter Stiefelhagen 